\title{
Impacto do Treino Proprioceptivo na Prevenção em Lesões de Atletas de Basquetebol
}

Eloiza Bragança de Oliveira Martins ${ }^{1}$, Giandra Rafaela Ramão ${ }^{1}$, Marina Harumi Schmoller Kubo ${ }^{1}$, Talia Regina Zilch', Maurícia Cristina de Lima² e Fábio Luis Perpétuo ${ }^{3}$.

1. Acadêmicas do $2^{\circ}$ e $3^{\circ}$ do curso de Graduação em Fisioterapia no Centro Universitário Uniamérica.

2. Fisioterapeuta, Mestre em reabilitação e inclusão, doutorada em Saúde Pública pela USP, docente do cur so de fisioterapia do Centro Universitário UniAmérica.

3. Fisioterapeuta. Docente do curso de fisioterapia e Pós-Graduado em Perito judicial trabalhista, Pilates e Reeducação Postural Global (RPG) pela Universidade Estadual do Oeste do Paraná (UNIOESTE). taliaareginna@gmail.come perpetuonewforme@gmail.com

\section{Palavras-chave \\ Basquetebol \\ Força Muscular \\ Lesão Esportiva \\ Membros Inferiores}

\begin{abstract}
Resumo: O basquete por conta de ser uma modalidade coletiva acaba levando a um amplo número de lesões correspondentes ao modo de jogo que contém contato direto entre os jogadores, ocorre movimentos rápidos em pequeno espaço. Encontra-se em estudos que joelho e tornozelo são os locais que ocorre maior número de traumas nes ta modalidade, como destaque entorses. Objetivo: Este estudo teve como objetivo avaliar a condição de lesões em joelho e tornozelo, das atletas de basquetebol. Metodologia: Participaram do estudo 17 jogadoras de basquetebol, com idade variando entre 14 a 18 anos, que competem representando a cidade de Foz do Iguaçu, Paraná, Brasil, colégio COC JK e UNIAMÉRICA. Foi utilizado 5 questionários desenvolvidos pelos acadêmicos. Resultado: Os resultados expressaram que das 17 atletas que participaram do projeto, 16 apresentaram algum tipo de lesão 94,11\%. Identificamos 18 lesões, sendo destas 7 (41,17\%) sendo lesões ocorridas no joelho e 11 (64,70\%) ocorridas no tornozelo. Da parte de tornozelo, a lesão mais encontrada foi entorse do joelho. Já na parte do joelho a lesão encontrada com maior índice foi tornozelo. Conclusão: Todos estes resultados foram de acordo com estudos retratados e mostram a necessidade de exercícios de propriocepção na percepção de diminuir a ocorrência destas lesões.
\end{abstract}

Artigo recebido em: 07.05.19

Aprovado para publicação em: 27.05.19

\section{INTRODUÇão}

O basquetebol é um esporte grupal que foi desenvolvido em 1891, no Estados Unidos, sendo uma categoria esportiva de relação direta entre o oponente, a probabilidade de lesões são diversas. Além disso, as mo vimentações específicas da modalidade tais como: aceleração, desaceleração, impulsão, giros, corte súbito da jogada, movimentos laterais e salto em ambiente pequeno, podem também sujeitar as pessoas a lesões osteomioarticulares, em especial nos membros inferiores (ZBOROWSKI et al., 2016).

As características biomecânicas principais são a corrida curta, o salto, e arremesso, a aceleração, a força, a defensão, a coordenação, o autodomínio, a habilidade e a percepção periférica. O dever de vitórias e superresultados nos esportes de alta rivalidade e os efeitos da abundância de treinos e competições, circunstâncias importantes para alcançar o ápice esportivo, apresentam um número evolutivo de lesões do sistema locomo tor dos jogadores de nível avançado, cujas causas teoricamente podem ser responsabilizadas a ausência de ações preventivas, stress competitivo, volúpia atlética e psicossomáticos (GANTUS, 2002).

O corpo compõe-se de 4 tecidos essenciais, muscular, nervoso, epitelial e tecido conjuntivo, cada um com uma definida função, na juntura destes tecidos são criados estruturas que atuam juntas em sistemas. 
Dentro do sistema muscular temos o músculo esquelético, que em geral são fixos nos ossos em diferentes partes, ao contraírem geram o movimento desejado pelo ser humano. São mais de 600 músculos no corpo humano e 206 ossos, uns estão ligados a movimentação de articulações, esses movimentos são os planos sagital, frontal e transverso, e os eixos latero lateral, anteroposterior e longitudinal. Há inúmeros tipos de traumas como contusão, estiramento, entorse, luxação e fratura, todas estas levando a dor e a perda de sensibilidade (GOMES, 2010).

Uma contusão atlética é semelhante de qualquer problema médico ocorrido durante a prática esportiva, podendo levar o atleta a perder parte ou todo treinamento para a competição ou limitar seu rendimento. Lesão esportiva é qualquer limitação das atividades do atleta no mínimo por um dia após a sua ocorrência. Pode haver ainda dois tipos principais de lesões esportivas: por pequenos traumas frequentes e traumas agudos. As lesões no basquetebol podem ser caracterizadas pela localização anatômica ou tipo da lesão, como as quedas que podem causar esfolamentos, fraturas e traumas, os entorses interfalângicos e metacarpo com falanges, os entorses e as tendinites do joelho e tornozelo (BORGES, 2015).

O joelho é certamente a articulação em geral mais exposta do esportista. A patologia macrotraumáticas mostra relativamente menos fratura do que as outras articulações, porém expõe violentamente meniscos e ligamentos. É uma das articulações mais comumente lesionadas em decorrência de sua estrutura anatômica, de sua exposição a forças externas e das exigências funcionais a que está subordinado. As lesões dos ligamentos do joelho encontram-se entre os problemas mais comuns (Ligamento Colateral Medial - LCM) e significati vos (Ligamento Cruzado Anterior - LCA) (CAMPOS, 2014).

O joelho sendo articulação intermédia do membro inferior tem assim um papel importante principalmente a nível motor e deve ter em cuidado quando é afetado fisicamente. Existem várias luxações ocorridas no joelho como, luxação da rótula essa luxação da patela é identificada pelo seu deslizamento para fora do sulco supratroclear do fêmur (CAMPOS, 2014).

As lesões no tornozelo são responsáveis por $45 \%$ das lesões no basquete, entorses sofridas no tornozelo leva o atleta a novas entorses e a sintomas residuais em até $40 \%$ das vezes. O tornozelo é uma estrutura que consiste em 26 ossos irregularmente moldados, 30 articulações sinoviais, mais de 100 ligamentos e 30 mús culos agindo no segmento. Sendo 12 destas articulações indispensáveis para os movimentos funcionais de pé e tornozelo durante as atividades (CAMPOS, 2014).

As entorses de tornozelo ocorrem durante a prática de basquetebol. Aqui no Brasil, certamente a lesão do joelho está muito mais relacionada ao basquetebol. Uma vez sofrido a entorse do tornozelo, a chance de um segundo episódio pode tornar-se bastante aumentada. O mais comum de torção no tornozelo é provocado por uma sobrecarga em inversão e pode resultar em ruptura parcial ou completa do ligamento talo fibular anterior (LTFA); o ligamento talofibular posterior é rompido somente com sobrepeso em inversões excessivas. Dependendo da gravidade, a cápsula articular arrisca-se de ficar afetada, resultando em sintomas de artrite aguda (TORRES, 2004).

A prática de exercícios proprioceptivos evolui o senso de posição articular e abstém-se que as lesões ocorram (DOVER et al., 2003).

A prática constante desses exercícios auxilia a permanecer um excelente retorno do sistema somatossensorial, comprovando na manutenção do equilíbrio (GAUCHARD, 1999).

Os exercícios proprioceptivos que compõe um programa de treinamento, as fases de uma reeducação proprioceptiva; e ainda analisar a contribuição desses exercícios na prevenção de lesões nos joelhos dos atletas. Para tal foi feita uma revisão literária, utilizando-se de livros, artigos e sites da internet. A utilização de 
exercícios proprioceptivos contribuiu para a diminuição do índice de lesões nos joelhos de atletas (ROCHA. , 2008).

Várias definições de lesão têm sido defendidas ao longo dos tempos, das quais podemos salientar algumas. Define como qualquer tipo de ocorrência, de origem traumática ou de sobreuso, da qual resulte a inca pacidade funcional, obrigando o atleta a interromper a sua atividade, não participando, em pelo menos, um treino ou jogo (LOPES, 2008).

Este estudo teve como objetivo avaliar a condição de lesões em joelho e tornozelo, das atletas de basquetebol.

\section{FundamentaÇão Teórica}

O basquetebol como um esporte de contato, apresenta grandes lesões, seja com a bola, com o impacto, com outro atleta, torções desequilíbrio. É um esporte que exige desenvolvimento motor fica se mais expostos e propensos às lesões causadas pela prática do esporte (MONTEIRO, 2013).

É definido como propriocepção, qualquer informação postural, posicional, levada ao Sistema Nervoso Central, pelos receptores dos músculos, tendões, ligamentos, articulações ou pele. A propriocepção também é definida como a consciência dos movimentos produzidos pelos nossos membros (MONTEIRO, 2013). Os proprioceptores são receptores que são localizados nos músculos, aponeuroses, tendões, ligamentos, arti culações e no labirinto cuja função reflexa é locomotora ou postural. Podem gerar impulsos nervosos, conscientes ou inconscientes. Os primeiros vão atingir o córtex cerebral e permitindo que, mesmo estando de olhos fechados, aconteça a percepção do próprio corpo, seus segmentos, da atividade muscular e do movimento das articulações. Sendo, portanto responsáveis pelo sentido de posição e de movimento (cinestesia) (MONTEIRO, 2013).

Os impulsos nervosos proprioceptivos inconscientes não despertam sensações; são utilizados pelo sistema nervoso central para regular a atividade muscular, através do reflexo, meio tático ou dos vários centros envolvidos com a atividade motora, como o cerebelo. Em resumo: Os proprioceptores são essenciais para informar ao nosso cérebro a noção de posição dos membros, e informação de posicionamento corporal é essencial para o controle dos movimentos. Moléculas anfipáticas, isto é, possui uma região polar (cabeça hidrofílica), tendo afinidade por água, e outra região apolar (calda hidrofóbica), que repele a água. Essa característica é fundamental para estabelecer uma interface entre o meio intracelular e o meio extracelular (MONTEIRO, 2013).

A propriocepção é dividida em 4 funções sensitivas distintas e separadas, sendo estas: Sensação de mo vimento passivo; é considerada como um produto de sensações induzidas por forças externas que resultam na alteração da posição do membro sem contração muscular. Cinestesia: sensação do movimento ativo, sofrendo alteração do movimento ou posição do membro com o músculo em contração (tem a capacidade de perceber e reconhecer movimentos e a mobilização articular). Estagnosia; percepção da posição de um membro no espaço. Dinamaestesia; presença de tensão e percepção da força aplicada durante uma contração voluntária. O controle neuromuscular é responsável pelas respostas eferentes apropriadas ao impulso proprioceptivo aferente (FABIANE, 2012).

Os mecanorreceptores são neurônios sensitivos ou aferentes periféricos que se localizam nos tecidos capsulares, ligamentares, tendões, músculos e pele. Os mecanorreceptores são classificados em 4 tipos sendo este tipo I, II, III, IV, os do tipo I e II encontram-se localizados na cápsula articular, já os do tipo III são en- 
contrados nas estruturas ligamentares os do tipo IV são representados por fibras nervosas não mielinizadas ou terminações (FABIANE, et al., 2012).

Cinestesia, é a capacidade em reconhecer a localização espacial do corpo, sua posição e orientação, a força que os músculos exercem e a posição de cada parte do corpo em relação às demais, sem utilização da visão. Este tipo de percepção permite a manutenção do equilíbrio postural e a realização de diversas atividades. Resulta da interação das fibras musculares que trabalham para manter o corpo na sua base de sustentação, de informações táteis e do sistema vestibular (MONTEIRO, 2013).

No entanto, os exercícios proprioceptivos demonstram uma grande ação profilática e de reabilitação em lesões musculoesqueléticas, pois exigem da modalidade sensorial maior precisão para obtenção de informações referentes à sensação de movimento e posição articular, com base em elementos de outras fontes que não a visual, a auditiva ou a cutânea superficial. Ao praticar alguma modalidade esportiva o atleta está sujeito há vários tipos de lesões, seja por traumatismo local direto, seja por sobrecarga repetitiva. Seu padrão neuromuscular se altera profundamente, assim como suas atividades proprioceptivas, que ao longo do tempo poderá influenciar negativamente em todas as suas valências físicas, reduzindo o desempenho geral, principalmente pela presença da dor, edema, isquemias, tensão muscular, contratura muscular reflexa, que são fatores limitantes (MONTEIRO, 2013).

Durante a contração muscular, o OTG descarrega um impulso nervoso capaz de inibir a contração muscular e provoca o relaxamento do músculo. Por esse motivo, o órgão tendinoso de Golgi é um sistema aferente inibitório, enquanto o fuso muscular é excitatório (JÚNIOR, 2006).

O Órgão Tendinoso de Golgi (OTG) está localizado no tendão com uma série de fibras musculares. O OTG serve como um dispositivo de segurança que ajuda a impedir uma geração de força excessiva durante a contração muscular (HOWLEY, 2005).

As lesões podem ocorrer de acordo com o esporte praticado, em partes específicas do corpo em que são extremamente exigidas. Este estudo é diretamente direcionado às lesões decorrentes aos treinamentos exaustivos e a máxima exigência do melhor resultado de jogadores de basquetebol. Lesões leves: requer atenção ou tratamento, mas sem interromper a atividade esportiva. Lesões moderadas: requerer tratamento e limita a participação do jogador em sua atividade. Lesões graves: ocorre um tempo maior da atividade esportiva, com hospitalizações frequentes e intervenções cirúrgicas. Lesões graves que levam a um grande prejuízo: impede o esportista de recuperar seu nível de rendimento ou funcionamento prévio, obrigando-o modificar sua forma de praticar esporte, sendo necessário mudar de atividade e fazer um trabalho de recuperação permanente para evitar recidiva. Lesões graves que provocam inatividade permanente: impedem os esportistas de voltarem a praticar atividades com a mesma intensidade que era praticada antes, tendo que fazer ajustes drásticos em sua forma de vida (ZBOROWSKI et al., 2016).

O entorse de tornozelo é baseada em uma área afetada e divide a lesão em três tipos: estiramento ligamentar: ocorre o estiramento dos ligamentos, mas sem que ocasione a ruptura do mesmo, causando inchaço e dor. Lesão ligamentar parcial: ocorre parcialmente a ruptura dos ligamentos e instabilidade articular causando edema, rigidez articular, dor e inchaço. Lesão ligamentar total: Rompimento total dos ligamentos e falta de firmeza no pé ao andar. O uso de anti-inflamatórios não-hormonais mostra diminuição da dor e edema, com melhora precoce da função articular (RODRIGUES, 2009).

Entorse em eversão envolve mecanismo de lesão de eversão e rotação externa. Entorses no complexo medial do tornozelo são menos comuns porque a biomecânica e anatomia da articulação do tornozelo permitem menor amplitude de eversão. O ligamento principal da face medial do tornozelo é o ligamento deltóide, 
que é composto pelos ligamentos tíbio talar anterior e posterior, o ligamento talocalcâneo, e os ligamentos tíbio navicular. Os ligamentos superficiais atravessam a talocrural e subtalar, enquanto que os ligamentos profundos passam pela articulação subtalar. As fibras o ligamento deltóide limitam a eversão do tornozelo, ex tensão e flexão (BORING, 2014).

Lesão são alterações de um tecido devido a alguma patologia ou algum trauma, podendo acarretar perda de função muscular. Lesões são divididas e caracterizadas em diretas ou indiretas, parciais ou totais, traumáticas e atraumáticas. As diretas agravam mais atletas de contato e bons exemplos destas lesões são contu sões e lacerações, já as indiretas estão mais presentes em atletas individuais. Nas lesões caracterizadas parciais a força muscular está baixa mas mantém a capacidade contrátil, diferente das totais que a movimentação articular pode não existir. Nas traumáticas temos também as lacerações e contusões junto com estiramentos, e nas atraumáticas encontramos cãibras e dor muscular tardia. Em lesões musculares ocorre um processo de cicatrização onde contém o processo inflamatório com as rupturas das fibras, este processo inflamatório pode ser uma inflamação crônica ou aguda, dependendo do tempo da lesão (BORGES et al., 2015).

A avaliação da força muscular nos membros inferiores é indispensável para os praticantes de basquete, até para amadores, principalmente porque após um evento de lesão, que é comum ao esporte, ocorre um déficit de força entre o membro lesionado e o seu contralateral. Avaliar a força nas musculaturas é essencial para reconhecer desequilíbrios musculares, a dedução por meio da dinamometria isocinética, com o controle de velocidade de execução de movimento seria a alternativa ideal para isso, porém a ocupação deste aparelho é difícil devido ao seu alto custo (ZBOROWSKI et al., 2016).

\section{Metodologia}

O estudo caracterizou-se como uma análise e tratamento das lesões de joelho e tornozelo das atletas de basquetebol, a pesquisa foi realizada no ginásio de esportes flamengo esporte clube na cidade de foz do iguaçu/pr. Foi fundada em 2018, e onde possui parceria com a Uniamérica Centro Universitário até final de 2018, prestando auxílio em diferentes especialidades.

A amostra foi composta por 17 atletas do gênero feminino, na faixa etária de 14 a 19 anos, que se encaixaram nos critérios de inclusão, que estejam de acordo com o projeto e assinam o Termo de Consentimento Livre e Esclarecido - TCLE, esse documento demonstra, de forma explícita, o reconhecimento do sujeito da pesquisa como ser autônomo e melhor defensor de seus interesses. A proteção dos sujeitos da pesquisa cons titui a razão fundamental das Normas e Diretrizes brasileiras envolvendo seres humanos (APÊNDICE A).

Os critérios de inclusão são: necessárias as atletas serem do gênero feminino, jogar pela ABASFI (Associação de Basquete de Foz Do Iguaçu) e ser da faixa etária de 14 a 18 anos.

Os critérios de exclusão são: não ser atleta de basquetebol da Abasfi, não estar na faixa etária de 13 a 19 anos e não ser do gênero feminino.

Os materiais que foram utilizados neste projeto são: Cama elástica para reabilitação, Disco de equilíbrio, elástico, tabula lateral proprioceptiva, tábua proprioceptiva redonda e escada de agilidade.

O treino proprioceptivo teve duração de 2 meses, 2 vezes por semana e com um tempo máximo de 30 minutos, antes das atividades de quadra e academia.

Disco de equilíbrio: Colocar a parte plantar dos dois pés sobre o disco flexionando o joelho, manter durante 4 minutos com a tentativa de reter o equilíbrio. Cama elástica: Uma caminhada pisando primeiramente com o calcanhar na cama elástica depois com a ponta do pé no período de 3 minutos. Cama Elástica: Uma 
caminhada pisando primeiramente com a ponta do pé depois com o calcanhar no período de 3 minutos. Tábua Lateral Proprioceptiva: Colocar a parte plantar dos dois pés sobre a tábua flexionando o joelho, manter durante 4 minutos com a tentativa de reter o equilíbrio.

Prancha de Propriocepção: Colocar a parte plantar de um pé sobre o disco flexionando o joelho, manter durante 2 minutos tentando reter o equilíbrio, repetir com o outro membro. Escada De Agilidade: Comece com os dois pés fora da escada, de frente para o primeiro quadrado. Coloque o pé direito no primeiro quadrado e, de seguida, o esquerdo também. Desloque o pé direito para fora da escada, e depois o esquerdo, após isso desloque o pé direito para o segundo quadrado, e repita com o esquerdo. Repita até percorrer toda a escada. O intuito é de andar dois quadrados e voltar um, até chegar ao final da escada, repetir seis vezes começando somente com o pé direito após terminar as repetições, fazer novamente outras seis repetições começando somente com o pé esquerdo.

Escada De Agilidade: Colocar o pé esquerdo dentro do primeiro quadrado da escada deixando o pé direito fora da escada, dar um salto para o próximo quadrado trocando os pés, deixando pé direito dentro da escada e pé esquerdo fora da escada, fazer isso até chegar ao final da escada, repetir 6 vezes. Mini Bands elásticos em círculo: Colocar o elástico na perna, fazendo o agachamento primeira posição flexionando os joelhos, levantar ficando na posição de extensão dos joelhos após isso fazer a abdução de um membro inferior, repetir estes movimentos 40 vezes alternando a abdução do membro inferior. Bola: Sentar no colchonete colocar a bola embaixo do joelho (com o membro inferior estendido) e fazer força com o joelho para apertar a bola durante 2 minutos, depois trocar o membro inferior e repetir o mesmo exercício. Elástico Extensor: Colocar o elástico na parte plantar de um dos pés, tirar este membro do chão e fazer força com a planta do pé para fazer o movimento de flexão e dorsiflexão do pé durante 2 minutos, após terminar trocar de membro e repetir o processo. Elástico Extensor: Deitar no colchonete levantar um membro inferior até ficar na altura da sua cintura colocar o elástico na parte plantar do pé fazer o movimento de flexão e dorsiflexão do pé durante 2 minutos, após terminar trocar de membro e repetir o processo.

Na coleta de dados utilizamos os atributos sociodemográficos e o conhecimento sobre lesões, foi aplicado um formulário elaborado pelos autores, que consiste em 10 questões de múltipla escolha, onde medem a intensidade das lesões e cada questão possui duas possíveis respostas, que conforme refletem níveis de gravidade crescente de cada sintoma, para avaliar o nível que apresentava cada atleta (APÊNDICE B).

Para analisar a dor será utilizada a Escala visual analógica (EVA). Trata-se de umas linhas numeradas de 0-10. Em uma parte da linha é marcada “nenhuma dor” e na outra "pior dor imaginável”. Pede-se, então, para que o paciente avalie e indique na linha a dor presente naquele momento (ANEXO A).

As informações foram recolhidas, tabuladas e graficadas em arquivos de Planilha Eletrônica (Microsoft Office Excel, 2010). Sobre esses dados, serão utilizados os métodos da estatística descritiva para a análise quantitativa, tais como média e percentual.

\section{Resultados}

Foram avaliadas 20 atletas de basquetebol, destas foram excluídas 3, pelas seguintes questões: 2 participantes desistiram e 1 não participou 75\% do treino proprioceptivo. Portanto esta amostra final foi composta por 17 participantes com faixa etária de 14 a 18 anos, demonstrada abaixo na tabela 1, onde também demonstra os tipos de lesões ocorridas pelas mesmas. 
Tabela 1. Características sociodemográficas dos participantes do estudo

\begin{tabular}{|c|c|c|}
\hline \multicolumn{2}{|c|}{ Gênero } & \\
\hline Feminino & 17 & $100 \%$ \\
\hline Faixa Etária (anos) & & \\
\hline $14-15$ & 13 & $76,47 \%$ \\
\hline $15-16$ & 0 & $0 \%$ \\
\hline $16-17$ & 1 & $5,88 \%$ \\
\hline $17-18$ & 3 & $17,64 \%$ \\
\hline Tempo de Atleta (anos) & & $52,94 \%$ \\
\hline 01 a 03 & 9 & $35,29 \%$ \\
\hline 04 a 06 & 6 & $11,76 \%$ \\
\hline 08 a 10 & 2 & $41,17 \%$ \\
\hline Suplementação & 7 & $76,47 \%$ \\
\hline Anti-inflamatório & 13 & $29,41 \%$ \\
\hline Acompanhamento & 5 & \\
\hline fisioterapêutico & 5 & \\
\hline
\end{tabular}

Verifica-se também na tabela 1 que das 17 atletas participantes do projeto, 16 delas (94,11\%) apresentaram algum tipo de lesão, no joelho ou tornozelo. Todas as atletas são do gênero feminino, sendo 76,47\% delas na faixa etária entre 14 e 15 anos, 5,88\% com a idade entre 16 e 17 anos e 17,64\% entre 17 e 18 anos. Referente ao tempo de profissão como atleta, 53\% da amostra relata estar de 1 a 3 anos, 35\% de 4 a 6 anos, e 12\% de 8 a 10 anos. Das participantes 41, 17\% usam algum tipo de suplementação, 76,47\% tomam ou já to maram anti-inflamatório e 29,41\% já tiveram algum acompanhamento fisioterapêutico.

Gráfico 1. Lesão de tornozelo em armadoras e alas de basquetebol

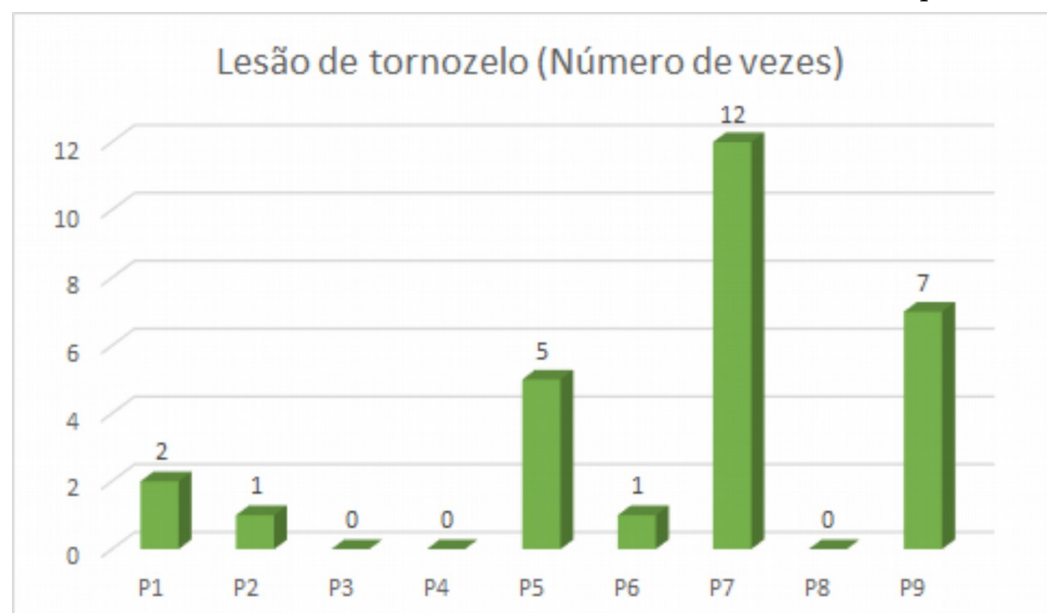


Verifica-se que no gráfico 1 as porcentagens do índice de lesão de tornozelo nas alas e armadoras, sendo estas as porcentagens encontradas: P1 7,14 \%, P2 3,57\%, P3 0\%, P4 0\%, P5 17,85 \%, P6 3,57 \%, P7 42,85\% e P9 25\%.

Gráfico 2. Lesões de entorse de joelho de armadoras e alas de basquetebol

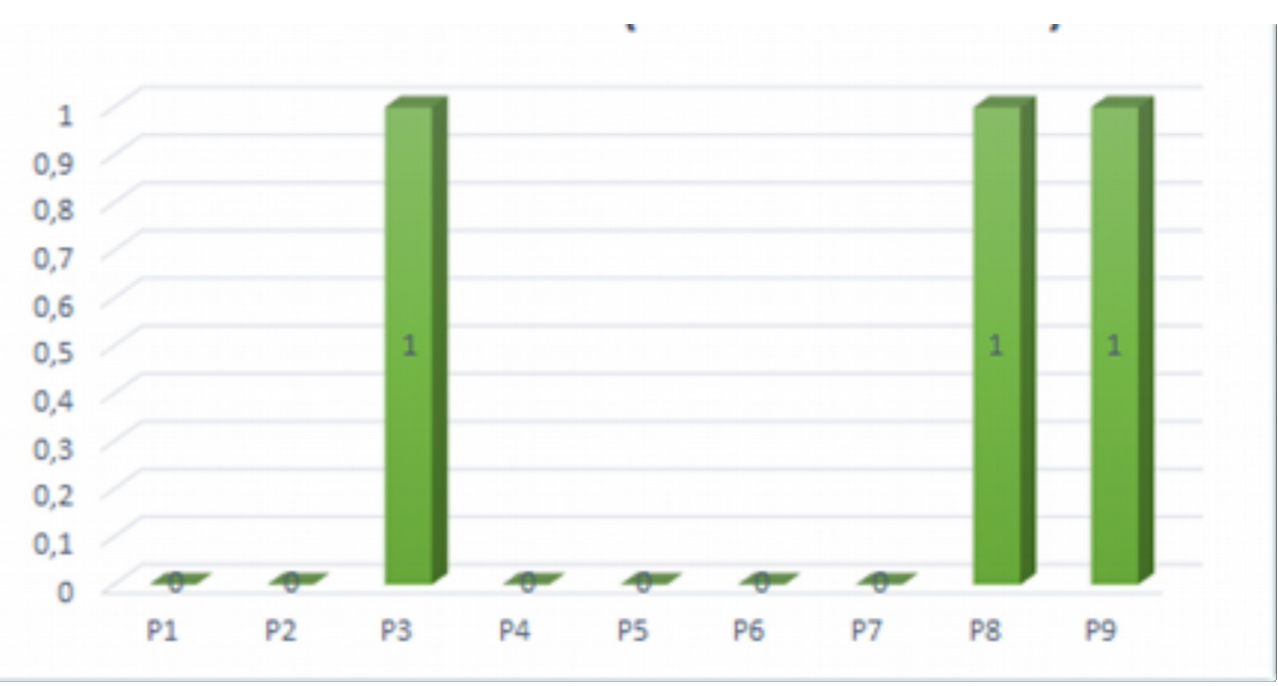

Observa-se no gráfico 2 as porcentagens de entorses de joelhos nas armadoras e alas, assim constando: P1 0\%, P2 0\%, P3 33,3\%, P4 0\%, P5 0\%,P6 0\%, P7 0\%, P8 33,3\% е P9 33,3\%.

Gráfico 3. Total de lesões e seus respectivos tipos

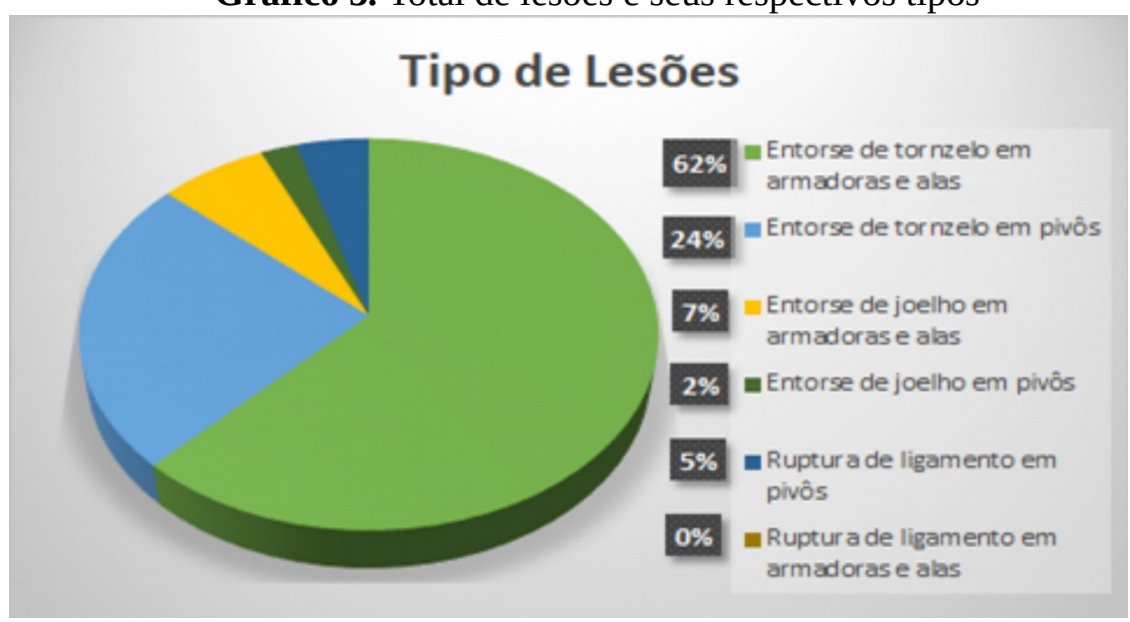

No gráfico 3 verifica-se a porcentagem de dos tipos de lesões: 62\% são armadoras e alas que apresentam entorse de tornozelo, $24 \%$ das pivôs com entorse de tornozelo, $7 \%$ das armadoras e alas apresentam entorse de joelho, $2 \%$ entorse de joelho em pivôs, $5 \%$ das pivôs apresentam ruptura de ligamento e $0 \%$ ruptura de ligamento em joelhos de armadoras e alas. 
Observa-se na tabela 2 o resultado do treino proprioceptivo, analisamos que a porcentagem de: Dor no treino de $100 \%, 41,17 \%$ apresentaram dor após o começo do treino e 58,82\% não apresentaram dor alguma, treino duas vezes na semana $88,23 \%$ acharam suficiente os treinos apenas duas vezes na semana e $11,76 \%$ acharam insuficiente, trinta minutos por treino 82,35\% acharam suficiente e 17,64\% não, 94,11\% acharam eficiente os exercícios e 5,88\% não, o rendimento nos treinos de basquete melhoraram em 94,11\% sentiram uma melhora e 5,88\% não e apenas 11,76\% apresentaram lesão após o início do treino de propriocepção e 88,23 não apresentaram lesão alguma.

Tabela 2. Resultado do treino proprioceptivo

\begin{tabular}{|c|c|c|c|c|}
\hline Dor no treino & 7 & $41,17 \%$ & 10 & $58,82 \%$ \\
\hline Duas vezes por semana & 15 & $88,23 \%$ & 2 & $11,76 \%$ \\
\hline Trinta minutos por treino & 14 & $82,35 \%$ & 3 & $17,64 \%$ \\
\hline Exercícios preventivos & 16 & $94,11 \%$ & 1 & $5,88 \%$ \\
\hline $\begin{array}{l}\text { Rendimento no treino de } \\
\text { Basquete }\end{array}$ & 16 & $94,11 \%$ & 1 & $5,88 \%$ \\
\hline $\begin{array}{l}\text { Lesão após o início do } \\
\text { treinamento }\end{array}$ & 2 & $11,76 \%$ & 15 & $88,23 \%$ \\
\hline
\end{tabular}

Na tabela 3 verifica-se a média do nível de dor de cada atleta relatado no início do treino $(5,29)$ e término $(1,41)$ do treino proprioceptivo, apresentando uma diminuição importante na comparação dos resultados.

\section{Discussão}

Em relação ao número de entorses do tornozelo sofrido pelas atletas, a quantidade encontrada nesta pesquisa foi bastante significativa, demonstrando a necessidade da implementação de um programa preventivo voltado ao problema, incluindo principalmente reforço muscular e trabalho proprioceptivo. Os autores se referem que na prevenção dos entorses possibilitaria uma diminuição significativa de recidivas ou mesmo do primeiro episódio de entorses (RUSSO et al., 2003).

Lesões por uso excessivo, definidas como lesões sem um evento específico e identificável responsável pelo início, podem ser um problema substancial nos esportes. Acredita-se que jovens atletas envolvidos em programas de desenvolvimento de elite tenham um risco particularmente alto de uso excessivo e lesões agudas. Neste grupo, altos volumes de treinamento e foram sugeridos para representar fatores de risco para lesão por uso excessivo. É necessário um conhecimento profundo da epidemiologia das lesões por excesso de uso em esportes juvenis para direcionar os fatores de risco de lesão e, assim, evitar a estagnação do desenvolvi mento de talentos relacionados a lesões e aumentar o retorno sobre o investimento em programas esportivos de elite. Yang encontrou uma incidência de lesão por uso excessivo de 2,0 por 1000 horas de exposição de atletas entre atletas de basquete da Divisão I da National Collegiate Athletic Association. Embora esses estudos indiquem que as lesões por excesso de uso em atletas jovens são comuns, elas podem subestimar a extensão total do problema. Isso ocorre porque a maioria dos estudos define a lesão como perda de tempo da parti- 
cipação, enquanto muitos atletas com lesões por sobrecarga continuam a participar, apesar da dor e do desempenho reduzido. Quando são utilizadas definições de perda de tempo, cerca de $90 \%$ das lesões por uso excessivo parecem não ser atendidas (RICHARDSON, et al., 2017).

Tabela 3. Nível de dor na escala visual analógica - EVA

\begin{tabular}{|c|c|c|}
\hline P1 & 7 & 0 \\
\hline P2 & 7 & 3 \\
\hline P3 & 6 & 3 \\
\hline P4 & 7 & 3 \\
\hline P5 & 7 & 2 \\
\hline P6 & 6 & 1 \\
\hline P7 & 4 & 2 \\
\hline P8 & 8 & 1 \\
\hline P9 & 4 & 0 \\
\hline P10 & 2 & 0 \\
\hline P11 & 5 & 3 \\
\hline P12 & 5 & 1 \\
\hline P13 & 5 & 2 \\
\hline P14 & 3 & 0 \\
\hline P15 & 7 & 0 \\
\hline P16 & 2 & 0 \\
\hline P17 & 5 & 3 \\
\hline Média & 5,29 & 1,41 \\
\hline
\end{tabular}

A princípio, os exercícios proprioceptivos foram introduzidos nos programas de reabilitação, mas com o passar dos tempos tais exercícios foram sendo utilizados no treinamento de atletas com o intuito de prevenir lesões. Vários estudos mostram que o treinamento sensório-motor ou proprioceptivo tem um efeito positivo na prevenção de lesões devido a dois fatores: 1) melhora no equilíbrio postural do atleta e 2) melhora do mecanismo de reflexos dos músculos que cruzam as articulações, sendo este o principal fator na prevenção. Os exercícios proprioceptivos são divididos em três fases. Na fase ativa estática ocasiona-se um desequilíbrio e o indivíduo deve permanecer 40 segundos tentando manter-se equilibrado. A fase ativa dinâmica compreende exercícios mais complexos, acrescentando superfícies de apoio na execução de cada movimento. Na fase de proteção da prática desportiva, realiza-se o ritmo, as superfícies de execução e as posições que simulem o gesto desportivo, tendo como objetivo principal incorporar os movimentos globais e específicos de cada desporto (ROCHA, 2008).

Quando ocorre uma lesão como a entorse de tornozelo, os proprioceptores ou mecanorreceptores ficam danificados, prejudicando assim a propriocepção. Para Freeman et al (1965), o mecanismo básico da instabilidade do tornozelo desenvolvido pela entorse é devido a lesão dos proprioceptores na cápsula articular e nos 
ligamentos. Essa instabilidade causa descoordenação motora, com interferência dos reflexos que dependem dos mecanorreceptores articulares (FREEMAN et al., 1965).

Especificamente para a proposta dos exercícios proprioceptivos como incremento para aumentar a estabilidade articular do tornozelo a presente pesquisa corrobora com estudos que demonstraram que esses exercícios têm uma grande ação profilática e de reabilitação em lesões musculoesqueléticas, pois exigem da modalidade sensorial, uma forma mais competente para obtenção de informações referente a sensação de movimento e posição articular (ISAKOV et al., 1997).

Durante a contração muscular, o OTG descarrega um impulso nervoso capaz de inibir a contração muscular e provoca o relaxamento do músculo. Por esse motivo, o órgão tendinoso de Golgi é um sistema aferente inibitório, enquanto o fuso muscular é excitatório (JÚNIOR, 2006).

As luxações patelares são lesões musculoesqueléticas frequentes vistas no departamento de emergência e representam 3\% de todas as lesões no joelho. Além disso, as luxações patelares representam uma das principais causas de hemartrose do joelho. A luxação patelar é uma entidade distinta de uma subluxação patelar, mas ocorre em um espectro de distúrbios denominados instabilidade patelar. As ocorrências mais comuns envolvem atividades esportivas que envolvem rápida desaceleração e torção, incluindo a rotação interna da plantação perna após o pé. No entanto, luxações também podem coincidir com eventos traumáticos, como impacto direto em um joelho parcialmente fletido (WOLFE, 2018).

Um entorse de tornozelo refere-se à ruptura dos ligamentos do tornozelo e representa aproximadamente 40\% das lesões atléticas. 85\% dos entorses de tornozelo ocorrem no lado de fora (lado lateral) do tornozelo e são conhecidos como um entorse em inversão.Num entorse em inversão, o Ligamento Talofibular Anterior é o mais frequentemente lesado. Os ligamentos do tornozelo são nomeados de acordo com os ossos para os quais eles conectam. Neste caso, o LTA conecta ao osso tálus do tornozelo. A função do LTA é prevenir o deslocamento anterior do tornozelo (CAMPOS, 2014).

\section{Conclusão}

Com este estudo pode-se analisar que o treino proprioceptivo é uma terapia complementar e que merece mais atenção, esta técnica traz importantes contribuições no controle do condicionamento físico do atleta, se mostrando também eficiente na redução de dores frequentes, além de ser não invasiva e de fácil aceitação entre os pacientes.

O treino proprioceptivo favorece tanto a melhora do controle do equilíbrio, quanto a prevenção de lesões corporais dos praticantes. Em vistas desses achados, sugere-se que protocolos proprioceptivos sejam aplicados durante período e amostras maiores, com participação de grupo controle, para que se possa futuramente padronizar períodos e técnicas mais efetivas para este tipo treinamento.

Assim conclui-se que os pontos importantes desta pesquisa foram à redução dos níveis de lesões e o grau de intensidade das mesmas, porém sugere-se mais estudos com a contribuição desta técnica associada a outros tipos de tratamento como acompanhamento fisioterapêutico entre outros, com objetivo de atingir melhores resultados tanto na redução como na cessação de dor.

O estudo mostrou que 17 atletas que responderam os questionários, 16 (94,11\%) apresentaram algum tipo de lesão. Basquetebol é uma modalidade que exige contato, deslocamentos constantes e saltos repetidos, o que causa várias lesões, principalmente de joelho e tornozelo. 
Ficou evidente que as lesões de tornozelo foram predominantes sobre as lesões de joelho. Das 18 lesões relatadas, 11 ocorridas no tornozelo, o que corresponde a $62 \%$ de todas as lesões. As lesões de tornozelo, principalmente entorses foram as mais frequentes. Esse resultado é semelhante ao encontrado em outras modalidades esportivas, que exigem um contato maior entre os jogadores, ou de saltos repetidos. No basquetebol é nítido que as lesões ocorrem principalmente na fase de aterrissagem após arremessos e rebotes.

O número de lesões pode ser diminuído com um trabalho que passa desde a orientação para o atleta fora da quadra mostrando a ele a importância da utilização de equipamentos adequados, da realização de aquecimento (tanto em treinos quanto em jogos) e também utilizar técnicas de propriocepção dentro da dinâmica do jogo e os exercícios de propriocepção que trabalhamos com elas duas vezes na semana. O trabalho proprioceptivo visa a recuperação de equilíbrio e estabilidade e o uso dos gestos esportivos é de suma importância na prevenção das lesões podendo ser aplicado desde a iniciação.

\section{REFERÊNCIAS}

BALDAÇO FO, Cadó VP, Souza J, Mota CB, Lemos JC, Fisioter Mov. 2010 abr/jun;23

BORGES, P.P. et al. Lesões no Basquetebol, Caxias do Sul - RS, de 15 a 17 de Setembro de 2015.

BORIN, G. Entorse em eversão de tornozelo, 2014.

CAMPOS, S.J. Lesões do joelho, Projeto Apresentado no Programa de Técnico em Radiologia do Colégio Tableau, como complementação da disciplina para obtenção do título de Técnico em Radiologia, 2014.

CENNI, M. H. F. et al.Tendinopatia patelar: tardios do tratamento cirúrgico Tendinopatia patelar: resultados tardios do tratamento cirúrgico,2015.

COSTAS, S.M.L. et al. A prática na formação de atletas no basquetebol feminino, revista brasileira de ciências da saúde, 2012.

DARIO, B.E.S. et al. Lesões esportivas: um estudo com atletas do basquetebol bauruense. grad Gustavo Barquilha. Ms Reinaldo Monteiro Marques, 2010.

FABIANE E. C. A Propriocepção e sua Contribuição para a Manutenção da Estabilidade Articular Dinâmica, 2012.

FREEMAN, M.A. Instability of the foot after injuries to the lateral ligament the ankle. J Bone Joint Surg Br. 1965

GANTUS, M. C.\& ASSUMPÇÃO, J. D.,Epidemiologia das lesões do sistema locomotor em atletas de basquetebol,2002.

HOWLEY, P et al.,Órgão tendinoso de Golgi (OTG), 2005.

ISAKOV E, Mizrahi J. Is Balance impaired by recurrent sprained ankle? Br. J. Sports Med 1997.

JÚNIOR A.S. et al. Contração muscular, 2006.

LOPES, B.M.S.A Importância do Treino Proprioceptivo na Prevenção da Entorse do Tornozelo,2008.

MONTEIRO A.N. et al.,Órgãos sensoriais e proprioceptivos, propriocepção e movimento, Manaus 2013.

RICHARDSON, A. et al. Alta prevalência de lesões e doenças autorreferidas em atletas do sexo femininos talentosos, 2017.

ROCHA, S.D.S, Treinamento Proprioceptivo Na Prevenção de Lesões, Rio Verde - Goiás 2008. 
ROCHA, S.I. Membro inferior ossos e articulações, 2017.

RODRIGUES.F.L et al. Entorse de torno. Rev. Assoc. Med. Bras. vol.55 no.5 São Paulo 2009.

RUSSO, Andre F., MOREIRA, Dem Ûstenes. Avaliação fisioterapêutica na entorse de tornozelo: Uma visão curativa e profiltica. Revista Fisioterapia Brasil, v.4, n.4, p. 276-281, jul/ago 2003.

TORRES, S.F, Perfil Epidemiológico de lesões no esporte. Florianópolis, Universidade federal de Santa Catarina Programa de Pós-Graduação em engenharia de produção, 2004.

ZBOROWSKI, J.E. et al. Avaliação da influência do histórico de lesões de praticantes recreacionais de basquetebol no déficit de força muscular de membros inferiores, R. Perspect. Ci. e Saúde,2016.

WOLFE S et al.,Luxação, Joelho, Patela, Redução., fevereiro de 2018. 